Bulletin UASVM Food Science and Technology 70(2)/2013, 149-150

ISSN-L 2344-2344; Print ISSN 2344-2344; Electronic ISSN 2344-5300

\title{
Characterization of Black and Green Tea from Local Market
}

\section{Sonia A. SOCACI, Anca FĂRCAŞ, Camelia TOMELE, Liana SALANŢĂ, Luminiţa VÂRVA, Maria TOFANĂ}

Faculty of Food Science and Technology, University of Agricultural Sciences and Veterinary Medicine Cluj-Napoca, Romania; sonia.socaci@usamvcluj.ro

\begin{abstract}
The leaves from Camellia sinensis are used from ancient times for preparation of tea but also as raw material for different extracts which are used in food industry as well as in pharmaceutical or cosmetic products. Due to the increasing interest in tea health benefits, the aim of the present study was to characterize several brands of green and black tea found on local market, regarding their content in total phenolic compounds, flavonoids and antioxidant capacity. Total phenolics and flavonoids were determined spectrophotometrically using a modified Folin-Ciocalteu method, respectively a chromogenic system of $\mathrm{NaNO}_{2}-\mathrm{Al}(\mathrm{NO} 3)_{3}-\mathrm{NaOH}$ based method. The antioxidant capacity of each tea sample was assessed through the evaluation of free radical scavenging effect on 2,2-diphenyl-1-picrylhydrazyl. The results obtained for the green and black tea samples varied widely, depending on the tea variety. The antioxidant capacity of the analyzed teas ranged between 12.10 and 40.03\%RSA, while the total phenolic content was within 2090 and $6080 \mathrm{mg} \mathrm{GA} / 100 \mathrm{~g}$. The concentrantion in flavonoids was between 9.04 and $15.34 \mathrm{~g} / 100 \mathrm{~g}$ of tea.
\end{abstract}

Keywords: tea, phenolic compounds, flavonoids, antioxidant capacity

Introduction. Tea is the second most consumed drink all over the world (after water), playing an important role not only in the human diet but also in the economies of several countries (Palacios-Morillo et al., 2013; Cabrera et al., 2006). Originating from China, the dried leaves of Camellia sinensis, are used from ancient times to prepare the specific beverage with beneficial health properties due to its content in natural antioxidant compounds (polyphenols, minerals and vitamins). The healthy effects associated with the consumption of green or black tea, suggested by recent human studies, are: the reduction of risk of cardiovascular diseases and different forms of cancer, reduction of blood pressure, the presence of compounds with antiAlzheimer's effect, antibacterial and antivirasic activity, solar ultraviolet protection, bone mineral increase density, antilipogenic character, source of bio-essential elements (Cabrera et al., 2006).

Aims and objectives. Due to the increasing interest in tea health benefits, the aim of the present study was to characterize several brands of green and black tea found on local market, regarding their content in compounds with antioxidant activity. The main objectives were to assess the content of tea samples in total phenolic compounds and flavonoids and to determine their antioxidant capacity.

Materials and methods. All six tea samples (three of green tea and three of black tea) employed in the study were purchased from local supermarkets (Cluj-Napoca, Romania). The samples were codified as follows: CVF, CVB and CVG for the green tea samples, respectively CNL, CND and CNE for black tea samples.

Total phenolics compounds were determined spectrophotometrically using a modified Folin-Ciocalteu method (Singleton et al., 1999). Briefly, $2 \mathrm{~g}$ of tea leaves were infused in $200 \mathrm{~mL}$ boiling water for $2 \mathrm{~min}$. An aliquot of $0.1 \mathrm{~mL}$ of extract was mixed with $6 \mathrm{~mL}$ of water and 0.5 
$\mathrm{mL}$ of Folin-Ciocalteu reagent. After $4 \mathrm{~min}, 1.5 \mathrm{~mL}$ of $\mathrm{Na}_{2} \mathrm{CO}_{3}$ solution (7.5\%) was added and the samples were brought to final volume of $10 \mathrm{~mL}$ with water. All samples were allowed to stand for $2 \mathrm{~h}$ at room temperature, before measuring the absorbance at $725 \mathrm{~nm}$. Results were expressed as milligrams of gallic acid (GA) equivalents per $100 \mathrm{~g}$ of sample. The ultrasonic extraction and the analysis of flavonoids using a chromogenic system of $\mathrm{NaNO}_{2}-\mathrm{Al}(\mathrm{NO} 3)_{3}-$ $\mathrm{NaOH}$, from the samples was performed according to the method described by Zhu et al., 2010. The absorbance of the samples was measured at $500 \mathrm{~nm}$ and the results were expressed as $\mathrm{g} / 100 \mathrm{~g}$ of tea sample. The antioxidant capacity of tea sample was assessed through the evaluation of free radical scavenging effect on 2,2-diphenyl-1-picrylhydrazyl (DPPH) radical (Odriozola-Serrano et al., 2008). Using a Shimadzu UV-1700 PharmaSpec spectrophotometer, the absorbance of samples was measured at $515 \mathrm{~nm}$. Results were expressed as the percentage of the absorption value of samples comparing with the reference DPPH solution.

Results and Discussion. For the samples of green tea, the total phenolic content varied between 2090 and $6080 \mathrm{mg} \mathrm{GA} / 100 \mathrm{~g}$, while for the black tea samples it was between 2300 and $4320 \mathrm{mg} \mathrm{GA} / 100 \mathrm{~g}$. The content in phenolics per cup of tea $(200 \mathrm{~mL})$ was also calculated. Thus, the highest concentration in phenolic compounds was determined for the green tea CVF (121.6 mg GA/200mL), followed by CNL black tea sample (86.4 mg GA/200mL). Excepting the samples CVG and CNE which had a concentration in flavonoids of $10.05 \mathrm{~g} / 100 \mathrm{~g}$, respectively $9.04 \mathrm{~g} / 100 \mathrm{~g}$, all other tea samples had the content in flavonoids over $13.31 \mathrm{~g} / 100 \mathrm{~g}$. The largest flavonoids concentration was found in CNL black tea sample $(15.34 \mathrm{~g} / 100 \mathrm{~g})$, followed by CVB with $14.33 \mathrm{~g} / 100 \mathrm{~g}$. The antioxidant capacity of the samples ranged from $12.10 \%$ to $40.03 \%$ of DPPH inhibition, being usually higher for the green tea samples. The high content in total phenolics of CVF sample seemed to have a decisive impact on its antioxidant activity $(40.03 \%$ of DPPH inhibition) compared with the other ones. Nevertheless, the CNL sample presented the second antioxidant capacity $(25.83 \%)$, due to its content in phenolics compounds and flavonoids.

\section{Conclusion}

The present study evaluated the content in phytochemicals and antioxidant activity of several green and black teas from local market. The largest content in bioactive compounds was found in two green tea samples (CVF and CVB), but also in a black tea sample (CNL). Although the health benefits attributed to the consumption of green or black tea beverage since early ages, the researches regarding its bioactive constituents are still of current interest.

\section{REFERENCES}

1. Cabrera C., Artacho R., Gimenez R. (2006). Beneficial Effects of Green Tea-A Review. J Am Coll Nutr. 25(2): 79-99

2. Odriozola-Serrano I., Soliva-Fortuny R., Martin-Belloso O. (2008). Effect of minimal processing on bioactive compounds and color attributes of fresh-cut tomatoes. LWT 41:217-226

3. Palacios-Morillo A., Alcázar A., de Pablos F., Jurado J.M.(2013). Differentiation of tea varieties using UV-Vis spectra and pattern recognition techniques. Spectrochim Acta A. 103: 79-83

4. Singleton V. L., Orthofer R.M., Lamuela-Raventos R. M. (1999). Analysis of total phenols and other oxidation substrates and antioxidants by means of Folin-Ciocalteu reagent. Methods in Enzymology 299: $152-178$

5. Zhu H., Wang Y., Liu Y., Xia Y., Tang T. (2009). Analysis of Flavonoids in Portulaca oleracea L. by UV-Vis Spectrophotometry with comparative Study on Different Extraction Technologies. Food Anal. Methods. 3: 90-97 